\title{
ORIGINAL ARTICLE \\ Loss of the xeroderma pigmentosum group B protein binding site impairs p210 BCR/ABL1 leukemogenic activity
}

\author{
NL Pannucci ${ }^{1}$, D Li ${ }^{1}$, S Sahay ${ }^{1}$, EK Thomas ${ }^{2}, \mathrm{R} \mathrm{Chen}{ }^{1}$, I Tala ${ }^{1}, \mathrm{~T} \mathrm{Hu}{ }^{1}, \mathrm{BT}$ Ciccarelli ${ }^{1}, \mathrm{NJ}$ Megjugorac ${ }^{1}, \mathrm{HC} \mathrm{Adams} \mathrm{III}{ }^{1}, \mathrm{PL} \mathrm{Rodriguez}{ }^{1}$, \\ ER Fitzpatrick ${ }^{1}, \mathrm{D}$ Lagunoff $^{1}$, DA Williams ${ }^{3}$ and IP Whitehead ${ }^{1}$
}

Previous studies have demonstrated that p210 BCR/ABL1 interacts directly with the xeroderma pigmentosum group B (XPB) protein, and that XPB is phosphorylated on tyrosine in cells that express p210 BCR/ABL1. In the current study, we have constructed a p210 BCR/ABL1 mutant that can no longer bind to XPB. The mutant has normal kinase activity and interacts with GRB2, but can no longer phosphorylate XPB. Loss of XPB binding is associated with reduced expression of c-MYC and reduced transforming potential in ex-vivo clonogenicity assays, but does not affect nucleotide excision repair in lymphoid or myeloid cells. When examined in a bone marrow transplantation (BMT) model for chronic myelogenous leukemia, mice that express the mutant exhibit attenuated myeloproliferation and lymphoproliferation when compared with mice that express unmodified p210 BCR/ABL1. Thus, the mutant-transplanted mice show predominantly neutrophilic expansion and altered progenitor expansion, and have significantly extended lifespans. This was confirmed in a BMT model for B-cell acute lymphoblastic leukemia, wherein the majority of the mutant-transplanted mice remain disease free. These results suggest that the interaction between p210 BCR/ABL1 and XPB can contribute to disease progression by influencing the lineage commitment of lymphoid and myeloid progenitors.

Blood Cancer Journal (2013) 3, e135; doi:10.1038/bcj.2013.36; published online 16 August 2013

Keywords: chronic myelogenous leukemia; p210 BCR/ABL1; XPB; NER; DNA repair

\section{INTRODUCTION}

$\mathrm{BCR} / \mathrm{ABL}$ fusion proteins are the products of reciprocal translocations that are causally associated with Philadelphia chromosomepositive leukemias. ${ }^{1}$ Depending upon the position of the breakpoint within the $B C R$ locus, different fusion proteins are generated, resulting in different clinical outcomes. Thus, p210 BCR/ABL1 is responsible for virtually all cases of chronic myelogenous leukemia (CML), whereas p190 BCR/ABL is associated with a subset of ALL. ${ }^{1}$ Although there is a general agreement that the tyrosine kinase activity residing within the $A B L$ component of $B C R / A B L$ is the principle driving force behind Philadelphia chromosome-positive leukemias, domains that are contained within the BCR sequences are also required for transformation. ${ }^{2-5}$

Efforts to understand the genetic instability, which usually accompanies progression of CML from the chronic phase to the blast phase, indicate that DNA repair pathways, such as homologous recombination repair, non-homologous end joining and mismatch repair, may be altered in hematopoietic cells expressing p210 BCR/ $A B L 1{ }^{6-8}$ Such cells are resistant to apoptosis induced by chemotherapeutic agents and $\gamma$-irradiation, ${ }^{9-13}$ despite exhibiting a tendency to accumulate more DNA damage. ${ }^{14}$ Although the pathways downstream of $\mathrm{p} 210 \mathrm{BCR} / \mathrm{ABL} 1$ responsible for this phenotype have not been clearly defined, there is evidence suggesting that p210 BCR/ABL1-positive cells may have enhanced DNA repair capability. ${ }^{14}$ Some of the DNA damage observed may therefore actually represent intermediates in an accelerated process of repair.

Independent studies have also revealed a role for p210 BCR/ ABL1 in the regulation of nucleotide excision repair (NER), ${ }^{15,16}$ a mammalian DNA repair system that removes a wide range of structurally unrelated lesions, including those induced by UV radiation and alkylating agents. ${ }^{17}$ In myeloid cells, the overexpression of p210 BCR/ABL1 increases NER activity and decreases UV electromagnetic radiation subtype C (UVC)-mediated cytotoxicity, ${ }^{15,16}$ whereas in lymphoid cells the overexpression results in decreased NER activity and increased UVC-mediated cytotoxicity. ${ }^{15}$ Although an exact mechanism for these changes in NER is not known, it has been shown that both BCR and p210 BCR/ $A B L 1$ bind to an essential protein in the repair process: xeroderma pigmentosum group $B(X P B){ }^{18,19}$ XPB is a $3^{\prime}-5^{\prime}$ DNA helicase with associated ATPase activity that forms part of the core subunit of the transcription factor TFIIH, ${ }^{20,21}$ and is required for NER and transcriptional initiation. ${ }^{22}$

Whether or not the interaction between XPB and p210 BCR/ ABL1 is responsible for altered NER and whether it supports disease progression has not yet been determined. In this study we show that a p210 BCR/ABL1 mutant lacking the XPB-binding site is attenuated in its ability to drive myeloproliferation and lymphoproliferation in murine models for $\mathrm{CML}$ and B-cell acute lymphoblastic leukemia (B-ALL), but not in its ability to regulate NER.

\section{MATERIALS AND METHODS}

Molecular constructs and yeast two-hybrid analysis

The pAX142 mammalian expression vector and pAX142-bcr-abl have been previously described. ${ }^{23}$ pAX142-xpb contains a full-length cDNA for human XPB. pAX142-bcr-abl( $\Delta 674-695)$ encodes full-length,

${ }^{1}$ New Jersey Medical School - University Hospital Cancer Center, University of Medicine and Dentistry of New Jersey, Newark, NJ, USA; ${ }^{2}$ Division of Experimental Hematology, Cincinnati Children's Research Foundation, Cincinnati Children's Hospital Medical Center, Cincinnati, OH, USA and 3Hematology/Oncology Division, Children's Hospital Boston and Dana-Farber Cancer Institute, Harvard Medical School, Boston, MA, USA. Correspondence: Dr IP Whitehead, New Jersey Medical School - University Hospital Cancer Center, University of Medicine and Dentistry of New Jersey, Cancer Center H level, 205 South Orange Avenue, Newark, NJ 07101, USA.

E-mail: whiteip@umdnj.edu

Received 11 February 2013; revised 5 July 2013; accepted 12 July 2013 
hemagglutinin-epitope-tagged p210 BCR/ABL1, with an internal deletion of residues 674-695. The yeast two-hybrid constructs pGBT9-bcr(1-1271), pGBT9-bcr(1-413), pGBT9-bcr(491-880) and pGBT9-bcr(871-1271) have been previously described. ${ }^{24}$ pGBT9-bcr(491-668), pGBT9-bcr(491-681), pGBT9$b c r(491-691), p G B T 9-b c r(491-700)$ and pGBT9-bcr(491-727) contain cDNAs that encode the indicated residues of BCR. pGBT9-bcr( $\Delta 674-695)$ encodes full-length BCR with an internal deletion of residues 674-695. pGBT9-dbs and pGBT9-ect2 contain full-length cDNAs for murine Dbs and Ect2, respectively. The yeast two-hybrid constructs for full-length MYC (pGAD-myc), XPB (pGAD-xpb) and ubiquitin (pGAD-ubq) have been previously described. ${ }^{23,24}$ The MSCV-IRES-gfp retroviral vector has been previously described (Addgene, Cambridge, MA, USA). ${ }^{25} \mathrm{MSCV}-b c r-a b l / p 210$ IRES-gfp and MSCV-bcr-abl/p210( $\Delta 674-695)$-IRES-gfp contain full-length p210 BCR/ABL1 and the p210 BCR/ABL1 XPB-binding mutant, respectively. The pCL-Eco helper plasmid ${ }^{26}$ was kindly provided by Dr Saghi Ghaffari. All yeast two-hybrid analysis was performed as previously described. ${ }^{24}$

\section{Cell culture}

$\mathrm{NIH}$ 3T3, 293T and Phoenix-Ecotropic cells were maintained in Dulbecco's modified Eagle's medium supplemented with $10 \%$ fetal calf serum $(\mathrm{NIH}$ 3T3; Sigma, St Louis, MI, USA) or fetal bovine serum (Phoenix-Ecotropic, 293T; Gemini, Woodland, CA, USA). Ba/F3 cells were maintained in RPMI1640 media supplemented with 10\% fetal bovine serum (Gemini) and $10 \%$ WEHI-conditioned media. High-titer retrovirus was generated using Phoenix-Ecotropic packaging cells (ATCC, Manhassas, VA, USA) as previously described. ${ }^{27}$

\section{Protein expression and coimmunoprecipitation}

Western blot analysis and coimmunoprecipitation assays were performed as previously described. ${ }^{28}$ The following antibodies were used: anti-XPB (Abcam, Cambridge, MA, USA); anti-TFIIH p89, anti-HA and anti-c-MYC (S19, HAF7 and N-262, respectively; Santa Cruz, Santa Cruz, CA, USA); anti-c$A B L$, anti-BCR, anti-GRB2, anti-phospho-c-ABL (Tyr-245), anti-CRKL (32H4), anti-phospho-CRKL (Tyr207) (Cell Signaling, Danvers, MA, USA); and antiphospho-tyrosine (PY20; BD Biosciences, Franklin Lakes, NJ, USA).

\section{COMET assays}

Murine bone marrow cells were collected as previously described. ${ }^{27}$ Cells were cultured in media supplemented with granulocyte colony-stimulating factor, stem cell factor and thrombopoietin $(100 \mathrm{ng} / \mathrm{ml}$ each; Peprotech, Rocky Hill, NJ, USA) to promote myeloid growth. Myeloid cells (or $\mathrm{Ba} / \mathrm{F} 3$ cells) were infected by retroviral particles that encode MSCV-bcr-abl/p210 IRES-gfp, MSCV-bcr-abl/p210( $\Delta 674-695)-I R E S-g f p$ or cognate vector. At $48 \mathrm{~h}$ post infection, cells that express green fluorescent proteins (GFPs) were sorted on a FACSVantage SE (FACSDiVA; BD Biosciences). Sorted cells were plated $\left(2 \times 10^{5}\right)$ in 35 -mm dishes and were spun at 1000 r.p.m. for $10 \mathrm{~min}$. Media was removed and cells were irradiated with $10 \mathrm{~J} / \mathrm{m}^{2}$ of UVC light $(254 \mathrm{~nm})$, using a germicidal lamp (American Ultraviolet Company, Lebanon, IN, USA). After irradiation, media was replaced and cells were incubated for the indicated time points. Cells were then collected, washed in phosphate-buffered saline and then COMET assays were performed according to the manufacturer's instructions (Trevigen, Gaithersburg, MD, USA). Results were analyzed using comet score 15 software (TriTek, Sumerduck, VA, USA).

Ex-vivo analysis of murine hematopoietic progenitor cells MethoCult GF M3434, M3630 and M3534 (StemCell Technologies, Vancouver, BC, Canada) were used to detect and quantify mouse hematopoietic progenitors in the bone marrow, following the manufacturer's instructions.

Bone marrow transduction and transplantation

For CML induction, primary bone marrow transplantation (BMT) was done as previously described. ${ }^{27}$ For B-ALL induction, cells from non-5fluorouracil-treated donor mice were used. All experiments were performed on 12-week-old, female, BALB/c mice (Jackson Laboratories, Bar Harbor, ME, USA). All animal care, housing and experimentation was conducted in accordance with protocols approved by the Institutional Animal Care and Use Committee of UMDNJ-New Jersey Medical School. Evaluation of disease progression by histopathology and flow cytometry was performed as previously described. ${ }^{27}$

\section{RESULTS}

Localization of the docking site for XPB within BCR and p210 BCR/ ABL1

In a previous report, yeast two-hybrid analysis was used to demonstrate an interaction between full-length XPB and a fragment of BCR (residues 413-789). ${ }^{19}$ We used a similar approach to more precisely map the docking site for XPB to residues $681-691$ of $B C R$ (Figure 1a). A full-length $B C R(\Delta 674-695)$ mutant still interacts with two other BCR-binding partners, $\mathrm{MYC}^{24}$ and ubiquitin, ${ }^{23}$ thus confirming its structural integrity (Figure $1 \mathrm{~b}$ ). XPB does not interact with two other RhoGEF family members (Ect2 and Dbs, Figure 1c), confirming the specificity of the interaction. As the docking site for XPB is retained within p210 $B C R / A B L 1{ }^{19}$ a mutant lacking the putative XPB-binding site (p210 $\mathrm{BCR} / \mathrm{ABL} 1(\Delta 674-695)$ ) was constructed in a mammalian expression vector. Both mutant and wild-type p210 BCR/ABL1 were then co-expressed with XPB in 293T cells, and a coimmunoprecipitation assay was performed (Figure 1d). Whereas we are readily able to detect an interaction between XPB and p210 BCR/ABL1, only a weak interaction is observed between XPB and the mutant.

XPB binding is not required to support p210 BCR/ABL1 auto- and trans-kinase activity

To determine whether the tyrosine kinase activity of p210 BCR/ $A B L 1$ requires $X P B$ binding, we expressed both wild-type and mutant proteins in 293T cells and performed western blot analyses to examine the phosphorylation levels of known substrates of p210 BCR/ABL1 tyrosine kinase activity. ${ }^{29}$ An equivalent level of phosphorylated CRKL was observed in cells that express p210 BCR/ABL1 and the mutant when compared with vector controls, suggesting that the trans-kinase activity is unaffected by loss of XPB binding (Figure 1e). Similarly, when we examined lysates with an antibody that recognizes the Tyr-245 autophosphorylated form of p210 BCR/ABL1, an equivalent level of auto-kinase activity was observed (Figure 1e). Next we determined whether p210 BCR/ABL1 and the mutant have an equivalent ability to interact with GRB2. It has been previously shown that p210 BCR/ABL1 autophosphorylates on Tyr-177, creating a docking site for GRB2. ${ }^{5}$ As shown by coimmunoprecipitation assays (Figure 1f), both p210 BCR/ABL1 and the mutant interact with GRB2 to an equivalent level. This indicates that the interaction with GRB2 does not require XPB binding and confirms that the auto-kinase activity of the mutant is unchanged.

\section{p210 BCR/ABL1 can phosphorylate XPB on tyrosine in vivo}

It has been previously shown that XPB is tyrosine phosphorylated in cells expressing p210 BCR/ABL1. ${ }^{19}$ To determine whether this requires a direct interaction, we expressed fulllength XPB along with either p210 BCR/ABL1 or the XPB-binding mutant in 293T cells. We then immunoprecipitated XPB and performed a western blot with antibodies that recognize the total or phosphorylated form of the protein. As shown in Figures $1 \mathrm{~g}$, a high level of phosphorylated XPB is detected in lysates that contain p210 BCR/ABL1, but not in cells that express the mutant.

The interaction with XPB does not influence the effects of $p 210$ BCR/ABL1 on NER

In myeloid cells, overexpression of p210 BCR/ABL1 has been shown to increase NER activity and decrease UVC-mediated cytotoxicity, ${ }^{15,16}$ whereas in lymphoid cells the overexpression results in decreased NER activity and increased UVC-mediated cytotoxicity. ${ }^{15}$ We examined whether the XPB-binding mutant can similarly influence NER. For this analysis, we cloned both p210 
a

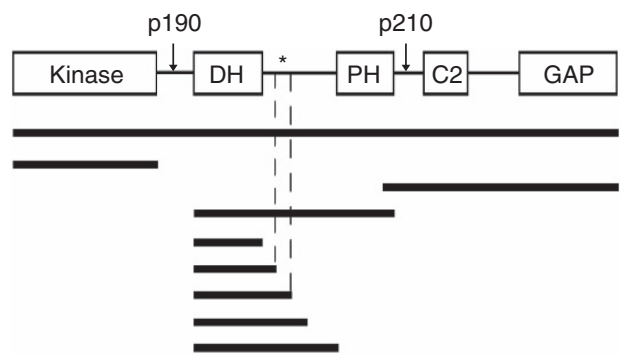

Residues

$1-127$

$1-413$

871-1271

$491-881$

$491-668$

$491-681$

491-691

491-700

$491-727$

d

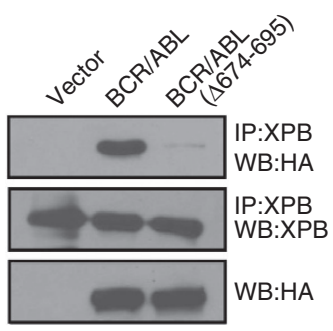

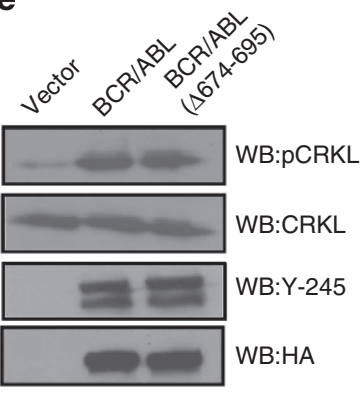

b

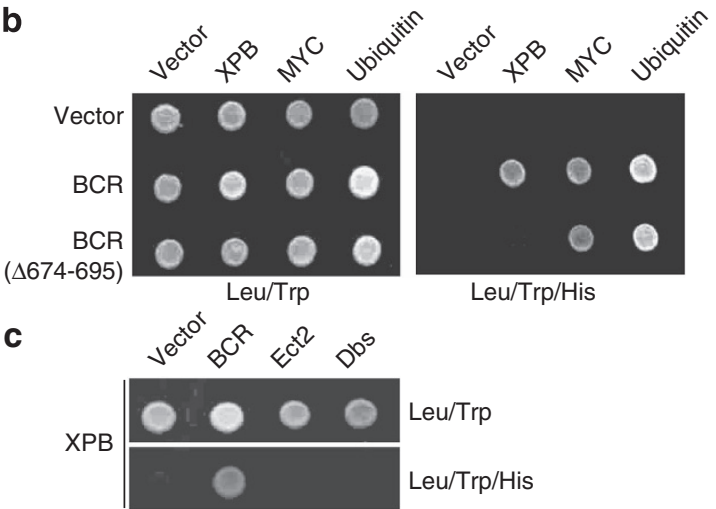

f

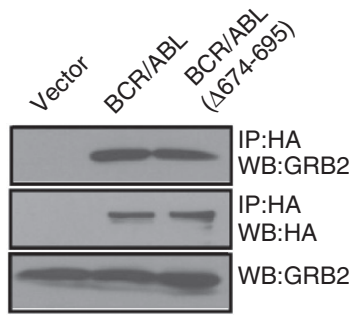

g

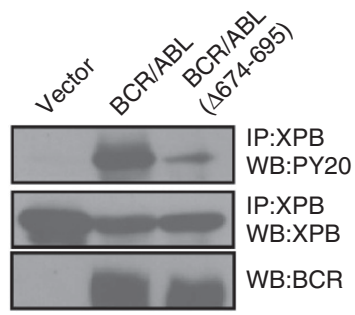

Figure 1. Mapping the XPB-binding site in BCR and BCR/ABL1. (a) Yeast two-hybrid mapping shows the XPB-binding site to be within residues $681-691$ of $\left.B C R{ }^{*}\right)$. Upper schematic shows the domain structure of the full-length $B C R$ protein, whereas the lines below indicate the regions of the protein included in the CDNA derivatives used for mapping. The breakpoints in BCR for p190 BCR/ABL and p210 BCR/ $\mathrm{ABL} 1$ are indicated by arrows. (b) $\mathrm{BCR}(\Delta 674-695)$ binds to c-MYC and ubiquitin, but not to XPB. Interactions between proteins are demonstrated by the ability to grow on histidine-deficient plates (Leu/Trp/His). (c) BCR does not interact with full-length Dbs or Ect2. (d) p210 BCR/ABL1 $(\Delta 674-695)$ is impaired in XPB binding. Cells were transiently co-transfected with full-length XPB and the indicated hemagglutinin-tagged BCR/ABL1 constructs. Lysates collected at $48 \mathrm{~h}$ were immunoprecipitated (IP) and/or examined by western blot (WB) analysis with the indicated antibodies (LC, loading control). (e) p210 BCR/ABL1( $\Delta 674-695)$ has normal auto- and trans-phosphorylation activity and (f) interacts with GRB2. Cell lysates were collected at $48 \mathrm{~h}$ and examined by WB analysis. (g) The interaction with p210 BCR/ $\mathrm{ABL} 1$ supports the phosphorylation of XPB on tyrosine. Lysates collected at $48 \mathrm{~h}$ were IP and/or examined by WB analysis with the indicated antibodies.

BCR/ABL1 and the mutant into MSCV-IRES-gfp. Retrovirus was then produced and was used to infect $\mathrm{Ba} / \mathrm{F} 3$ cells. Consistent with the 293T cells, an equal and elevated level of phosphorylated CrkL is detected in lysates that contain p210 BCR/ABL1 or the mutant (Figure 2a), suggesting that the tyrosine kinase activity is unaltered. Cells that express p210 BCR/ABL1 also show elevated levels of endogenous, phosphorylated XPB and this is not seen in cells expressing the binding mutant. Cells were then irradiated with UVC $\left(10 \mathrm{~J} / \mathrm{m}^{2}\right)$ and Comet assays were performed (Figure $\left.2 \mathrm{~b}\right)$. In control cells, a significant increase in NER is observed by $1 \mathrm{~h}$ post irradiation. Cells that express p210 BCR/ABL1 exhibit significantly reduced NER relative to control cells, which is consistent with previous observations. ${ }^{15}$ Cells that express the mutant have levels of repair equivalent to cells that express p210 $B C R / A B L 1$ at both $1 \mathrm{~h}$ and $3 \mathrm{~h}$ post irradiation. To examine NER in myeloid cells, bone marrow cells were collected from BALB/C mice and infected with retrovirus that contain p210 BCR/ABL1, p210 $B C R / A B L 1(\Delta 674-695)$, or cognate vector. Myeloid cells were selected by culturing in the presence of granulocyte colonystimulating factor, stem cell factor and thrombopoietin. Cells were then irradiated with UVC $\left(10 \mathrm{~J} / \mathrm{m}^{2}\right)$ and Comet assays were performed (Figure 2c). In control cells, a significant increase in NER was observed at $1 \mathrm{~h}$ post irradiation and, consistent with previous results, repair was significantly enhanced in cells that express p210 BCR/ABL1. ${ }^{15}$ An equivalent and significant increase in repair activity was also observed in cells infected with the binding mutant.
Loss of XPB binding is associated with reduced expression of c-MYC

It has been shown previously that c-MYC is stabilized by p210 $B C R / A B L 1^{\text {(ref.30) }}$ and is required for p210 BCR/ABL1 transformation. ${ }^{31}$ As c-MYC expression is known to be directly regulated by $X P B,{ }^{32,33}$ we also examined c-MYC expression in the $\mathrm{Ba} / \mathrm{F} 3$ cells that stably express p210 BCR/ABL1, or the mutant (Figure 2d). As expected, the c-Myc levels were elevated in cells expressing p210 BCR/ABL1 relative to vector controls. In contrast, c-MYC levels were significantly diminished relative to vector controls in cells that express the mutant.

The interaction with XPB influences transformation in murine bone marrow ex-vivo assays

To explore the role of the XPB interaction in the transformation of murine hematopoietic progenitor cells, bone marrow was collected from $B A L B / C$ mice and infected with retrovirus that contain p210 BCR/ABL1, p210 BCR/ABL1( $4674-695)$, or cognate vector. Bone marrow colony formation was assessed on media that supports growth of granulocyte-macrophage progenitors (GMP) (M3534), erythroid progenitors (BFU-E) (M3434) and B-cell progenitor cells (CFU-preB) (M3630). When we compare p210 BCR/ $A B L 1$, and the mutant, with vector on the M3434 media, we observe an equivalent number of BFU-E colonies (Figure $3 a$ ). In contrast, whereas p210 BCR/ABL1 shows enhanced growth of GMPs on M3534 media, the mutant is impaired in its ability to 
a

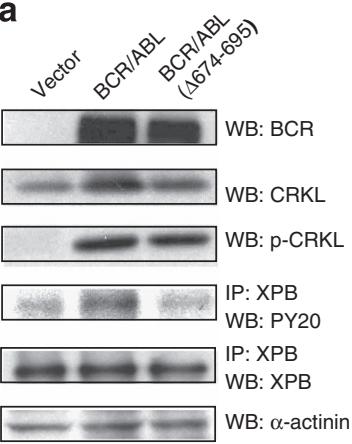

b

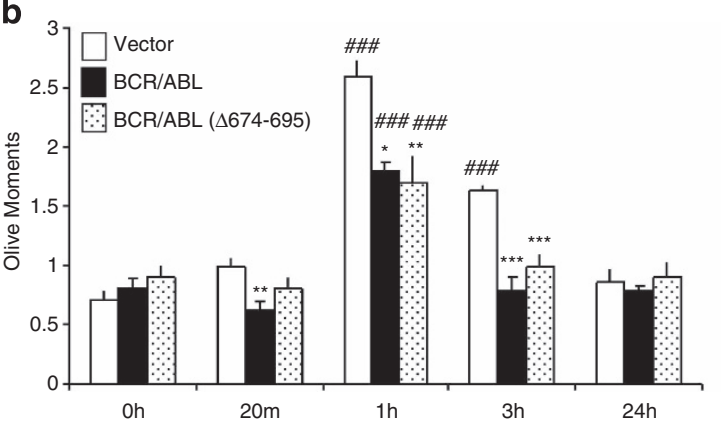

C

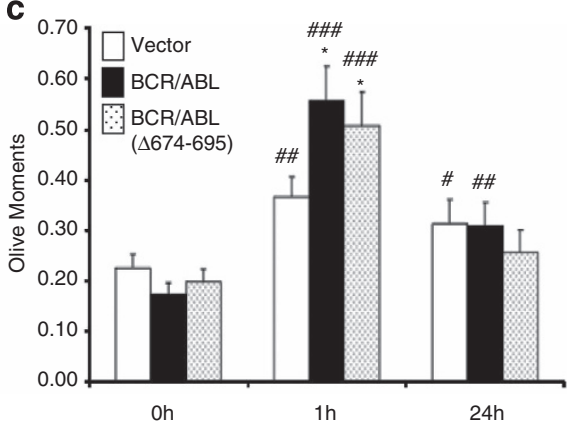

d

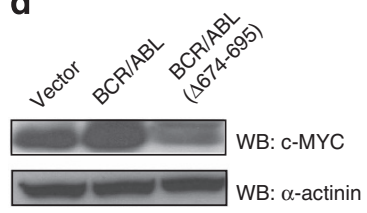

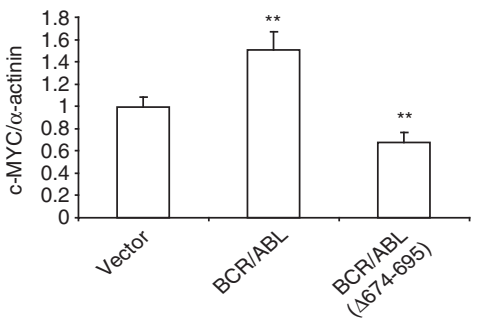

Figure 2. Regulation of NER by p210 BCR/ABL1 is independent of XPB binding. (a) Lysates collected from Ba/F3 cells that stably express p210 $\mathrm{BCR} / \mathrm{ABL} 1$, p210 BCR/ABL1 $(\Delta 674-695)$ or cognate vector at $48 \mathrm{~h}$ were immunoprecipitated (IP) and/or examined by western blot (WB) analysis with the indicated antibodies. (b) Ba/F3 cells or (c) primary murine myeloid cells that stably express p210 BCR/ABL1, p210 BCR/ABL1( $\Delta 674-$ 695) or cognate vector (MSCV-IRES-gfp (MIG)) were irradiated with UVC $\left(10 \mathrm{~J} / \mathrm{m}^{2}\right)$ and NER was measured at the indicated time points using COMET assays as described in Materials and Methods. Data shown are an average of at least three independent experiments. $P$-values were calculated using an analysis of variance $(P<0.05)$ followed by paired Student's $t$-tests. "Significance relative to the 0 time point and

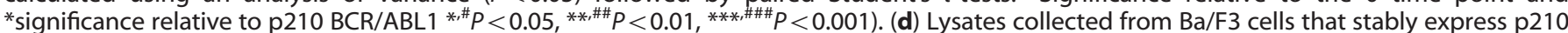
$\mathrm{BCR} / \mathrm{ABL}, \mathrm{p} 210 \mathrm{BCR} / \mathrm{ABL} 1(\Delta 674-695)$ or cognate vector at $48 \mathrm{~h}$ were examined by western blot $(\mathrm{WB})$ with the indicated antibodies. Left shows a representative blot. Quantified data shown on the right is fold expression relative to vector controls. Data is the average from three independent cell lines and shows s.d., and statistical significance relative to vector $\left({ }^{* *} P<0.01\right)$.

transform GMP. In the CFU-preB cell assay, both constructs exhibit transformation, but transformation by the mutant is significantly less than transformation by p210 BCR/ABL1. No colonies were observed on the vector control plates.

\section{XPB binding contributes to disease progression in a BMT model} for CML

We next determined whether the mutant was impaired in its ability to drive myeloproliferation in a murine model for CML. Consistent with previous reports, ${ }^{34-36}$ all the mice transplanted with p210 BCR/ABL1 became moribund within 28-35 days of transplantation (Figure 3b), displaying cachexia, increased respirations and a mottled coat. Examination of peripheral blood smears revealed massive leukocytosis (Figure 3c, top panel) and white blood cell (WBC) counts taken at death were elevated $(350,000 / \mu \mathrm{l})$. At death, all animals had splenomegaly with disruption of both the white and red pulp (Figure 3c, second panel). In the liver, granulocytes infiltrated both sinusoids and portal tracts (Figure 3c, third panel). As previously seen in other studies, ${ }^{34-36}$ large numbers of granulocytes were present in pulmonary capillaries together with extensive focal hemorrhage and consolidated regions (Figure 3c, fourth panel).

Mice transplanted with p210 BCR/ABL1( $1674-695)$ showed fewer signs of overt illness at the early stages of disease progression. Overall, mice had significantly longer lifespans (mean $=78.8$ days, Figure $3 b$ ), which was confirmed in two independent experiments ( $n=5$ for each experiment). Weekly peripheral blood smears revealed that myeloproliferation was occurring (Figure 3c, top panel) and WBC counts taken at death $(415,000 / \mu \mathrm{l})$ were comparable to those seen in the p210 BCR/ABL1 mice. Although splenic tissue architecture was similarly destroyed, liver architecture was better preserved in the mutant mice.
Lung capillaries in the mutant mice contained numerous granulocytes, but there was considerably less hemorrhage than in the p210 BCR/ABL1 mice.

Vector-transplanted mice ( $n=20$ total) had normal WBC counts $(\approx 13000 / \mu \mathrm{l})$ and remained disease free through 6 months post BMT (not shown).

Immunophenotyping at different points after transplantation reveal differences in disease progression

To directly compare disease progression, three mice from each group (including vector) were killed at days 16 and 30 post BMT and immunophenotyping was performed (Figure 4). At day 16 post BMT, over $50 \%$ of WBCs in the p210 BCR/ABL1 mice were GFP-positive compared with $\sim 25 \%$ for vector and mutant expressing mice (Figure 4a). Both the p210 BCR/ABL1 and mutant mice exhibited an approximately twofold increase in WBCs expressing the myeloid-specific marker, $C D 11 \mathrm{~b}$, relative to vector mice. Surprisingly, however, over $30 \%$ of the WBCs in the p210 BCR/ABL1-transplanted mice expressed a B-cell marker (B220), whereas the B-cell counts in the mutant-transplanted mice did not exceed $3 \%$. It is likely that this expansion of B cells in the p210 $\mathrm{BCR} / \mathrm{ABL}$ 1-transplanted mice accounts for the difference in total number of $\mathrm{GFP}^{+}$cells. Histologic examination performed at day 16 post BMT revealed the beginning of disease progression with little significant difference between the mice (Supplementary Figure 1).

Comparison of mice on day 30 post BMT revealed more dramatic differences in disease progression. Greater than $95 \%$ of the WBCs from the p210 BCR/ABL1 mice were GFP-positive and $70-80 \%$ of the cells stained positive for myeloid markers (Figure $4 \mathrm{~b}$ ). In comparison, only $50 \%$ of the WBCs from mutant mice were GFP-positive and only 35\% stained positive for myeloid 
a
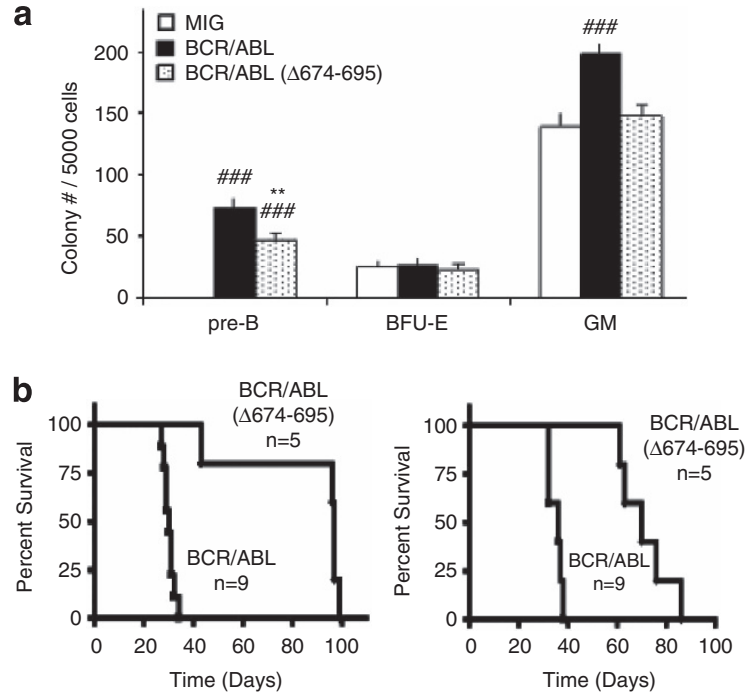

Vector
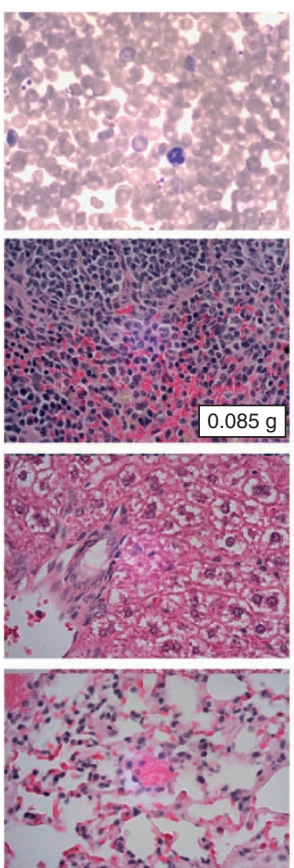

BCR/ABL
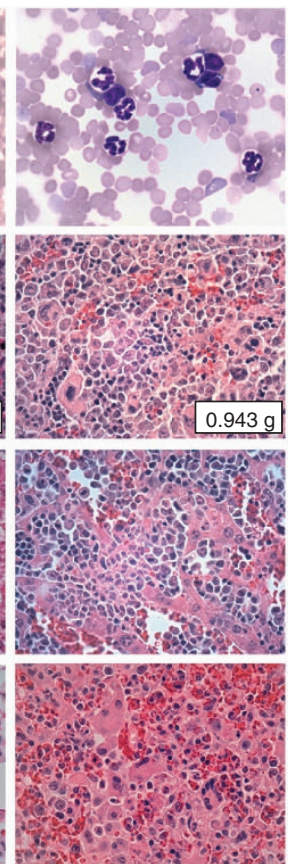

BCR/ABL ( $(4674-695)$
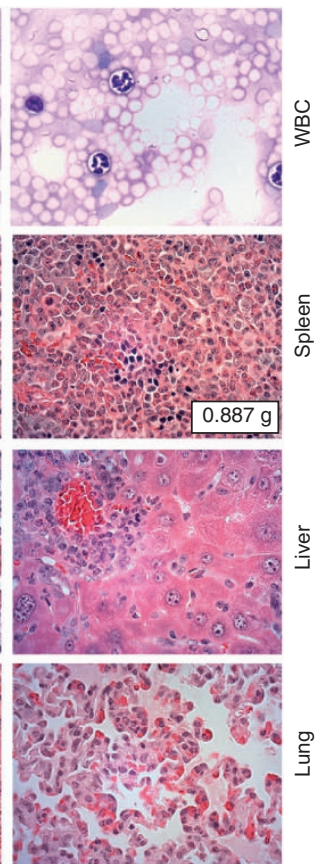

Figure 3. Loss of XPB binding alters the transforming potential of p210 BCR/ABL1 in murine ex-vivo assays and the BMT assay. Bone marrow was collected from BALB/c mice and infected with retroviral particles that encode MSCV-bcr-abl/p210-IRES-gfp, MSCV-bcr-abl/p210( $\Delta 674-$ 695)-IRES-gfp or cognate vector. GFP-positive cells were collected and either (a) plated in MethoCult media that supports the growth of both BFU-E and GMP (GM), or CFU-preB, or (b) transplanted into recipient mice. (a) Colonies were counted and expressed as the number of colonies per 5000 cells plated. Data shown are the average of three independent experiments and shows s.d., and statistical significance relative to p210 $\left.{ }^{*} P<0.05,{ }^{*} P<0.01,{ }^{* *} P<0.001\right)$. (b) Survival of mice transplanted with p210 BCR/ABL1 or p210 BCR/ABL1( $\left.\Delta 674-695\right)$. Kaplan-Meier curves were generated from two independent experiments as indicated. Mantel-Cox tests of the two survival curves yielded values of $P=0.0007\left(\chi^{2}\right.$-test $\left.=11.59\right)$ and $P=0.0017\left(\chi^{2}\right.$-test $\left.=9.851\right)$, respectively. $(\mathbf{c})$ Blood smears (top panel) were performed weekly to monitor disease progression. The representative smear shown was taken 21 days after transplantation. Spleen (inset shows spleen weight in grams), liver and lung tissues were collected at the time of death. Images shown are from a p210 BCR/ABL1 mouse that died at 27 days post BMT and a p210 BCR/ABL1 $(\Delta 674-695)$ mouse that died at 99 days post BMT.

markers. Expansion of the B-cell population was less apparent in the p210 BCR/ABL1-transplanted mice at day 30. Organ histology at day 30 also revealed differences between the groups, with mutant-transplanted mice having better preservation of liver and lung architecture than p210 BCR/ABL1-transplanted mice (Supplementary Figure 1).

Mice were also subject to immunophenotyping when they became moribund (Table 1). In order to determine whether there is a qualitative difference in myeloid expansion, cells were also examined for the expression of a granulocyte-specific marker $\left(\mathrm{Gr}^{+}\right)$. At death, all of the mice have predominantly myeloproliferative disease, although most still have slightly elevated B-cell counts. Although the percentage of $\mathrm{GFP}^{+} \mathrm{CD} 11 \mathrm{~b}^{+}$cells is equivalent in all tissues examined, the percentage of cells that are $\mathrm{GFP}^{+} \mathrm{Gr}^{+}$is significantly higher in mice transplanted with the mutant than in mice transplanted with p210 BCR/ABL1. This suggests that myeloid expansion in the mutant-transplanted mice is primarily restricted to neutrophils.

\section{Loss of XPB binding alters progenitor expansion}

In order to determine whether the impairment in disease progression and myeloid expansion could be attributed to differences in progenitor expansion, GFP-positive cells were examined from the bone marrow of p210 BCR/ABL1 and p210 $\mathrm{BCR} / \mathrm{ABL} 1(\Delta 674-695)$-transplanted mice at death (Figures $5 \mathrm{a}$ and $\mathrm{b}$ ). Surprisingly, the total number of progenitors is significantly increased in the mutant-transplanted mice, which is attributable to a large increase in GMP. Cell cycle analysis performed on the
GMs, CMPs and MEPs revealed no significant difference in either proliferative potential or sensitivity to apoptosis (Figure $5 \mathrm{c}$ ).

XPB-binding supports B-cell proliferation in a BMT model for B-ALL As mice transplanted with the XPB-binding mutant did not show the early B-cell proliferation seen in p210 BCR/ABL1-transplanted mice, we determined whether the mutant could drive lymphoproliferation in a murine model for B-ALL. ${ }^{34}$ Consistent with previous reports, mice transplanted with p210 BCR/ABL1 exhibited B-cell lymphocytosis when killed at day 20 and 38 post BMT (Table 2, p210 BCR/ABL1 mice 1-6). ${ }^{34}$ Between days 37 and 75, 10 of 13 mice succumbed to disease (Figure 6a), and necropsies performed at death revealed characteristic signs of lymphadenopathy and moderate splenomegaly (spleen weight $=0.2-0.5 \mathrm{~g}$ ). Flow cytometry performed on tissues from randomly selected mice showed a predominance of GFP ${ }^{+} / \mathrm{B}^{2} 20^{+}$cells (Table 2, p210 $\mathrm{BCR} / \mathrm{ABL} 1$ mice $7-10)$, a large proportion of which were $\operatorname{lgM}^{-} / \mathrm{BP}^{-1}{ }^{+}$, suggesting immaturity (data not shown). On day 76, the survival study was terminated and the three remaining p210 $\mathrm{BCR} / \mathrm{ABL} 1$ mice were killed and analyzed. One mouse showed clear signs of B-ALL (Figure 6b, Table 2, p210 BCR/ABL1 mouse 11), one showed no evidence of disease (not shown) and one showed expansion of $\mathrm{CD}_{11} \mathrm{~b}^{+}, \mathrm{B}_{2} 20^{+}$and $\mathrm{CD}^{+}$cells (not shown). In summary, out of 13 mice examined, 11 had immunophenotypes consistent with B-ALL.

In comparison with the p210 BCR/ABL1-transplanted mice, those transplanted with the XPB-binding mutant showed a significant increase in lifespan, with only one mouse dying within 
a

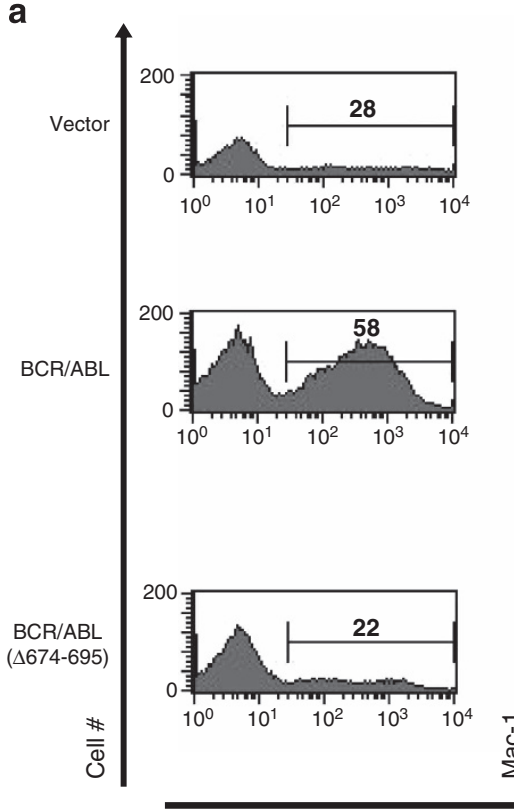

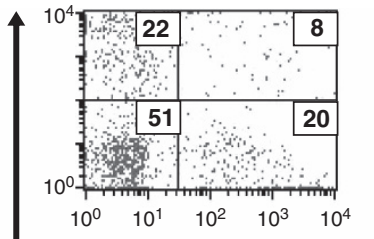
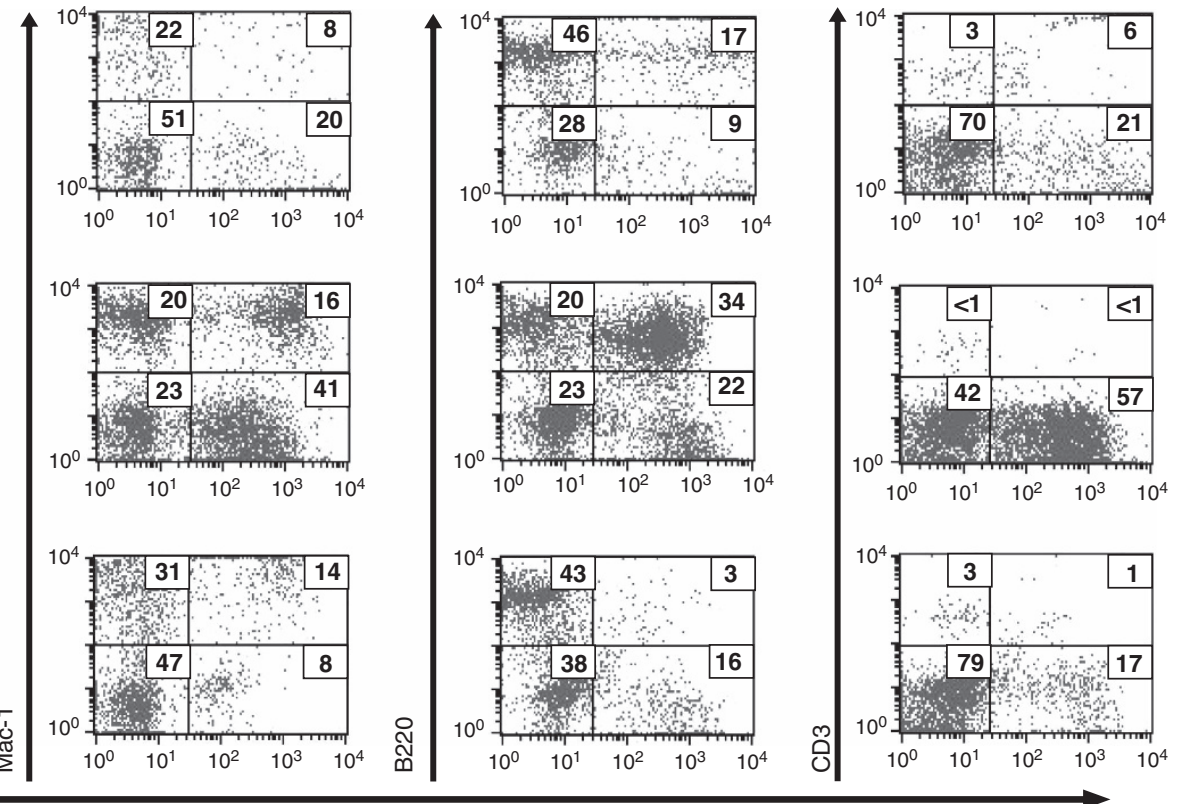

GFP

b

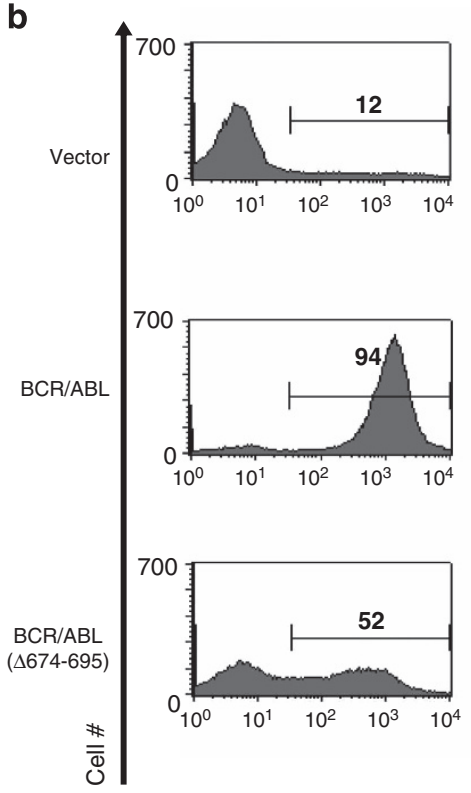

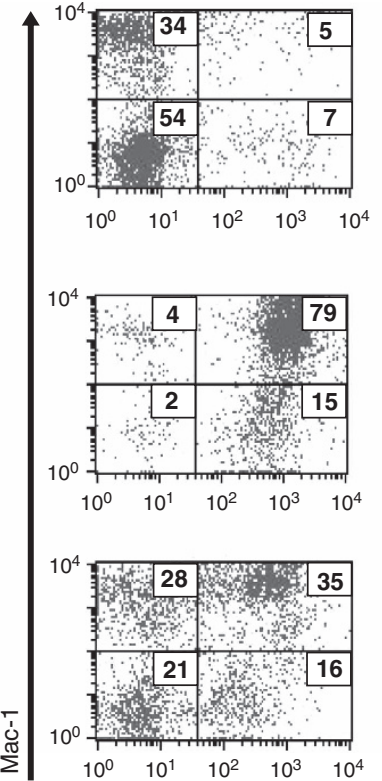
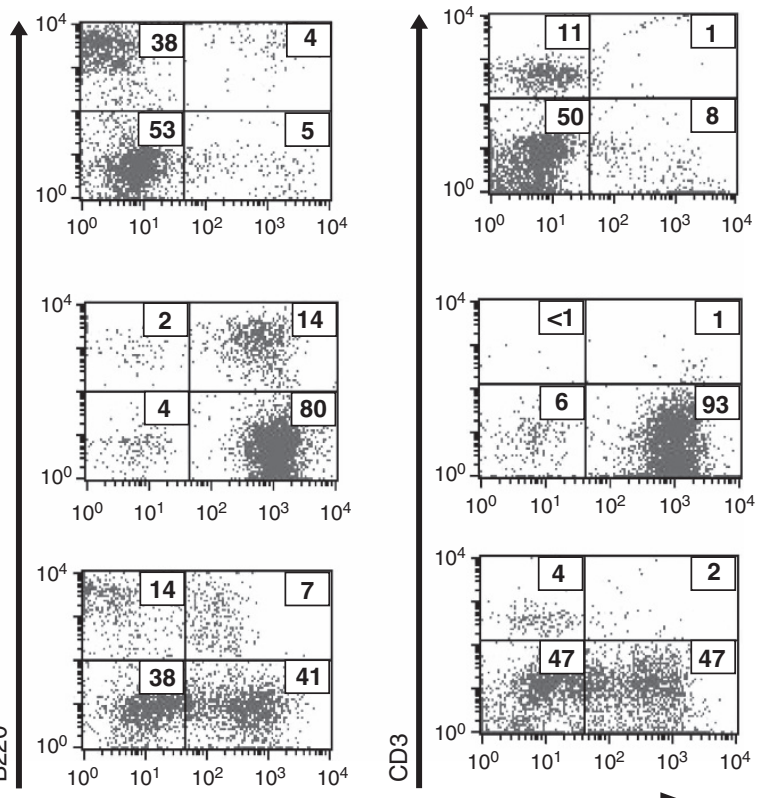

GFP

Figure 4. Comparison of immunophenotypes during early-stage disease progression in mice transplanted with p210 BCR/ABL1 or p210 BCR/ ABL1 $(\Delta 674-695)$. WBCs were collected from p210 BCR/ABL1, p210 BCR/ABL1( $1674-695)$ and vector-transplanted mice following elective killing on day 16 (a) and day 30 (b) post BMT, and were examined by flow cytometry for GFP expression. Cells were stained for CD11b, B220 and CD3 as indicated.

the time period covered by the survival study (Figure 6a, Table 2, p210 BCR/ABL1( $(674-695)$ mouse 7$)$. This mouse developed a large cervical tumor, which stained negative for CD11b, B220 and CD3 (not shown). Mice that were killed and examined at day 20 and 38 exhibited no signs of lymphocytosis (Table 2, p210 BCR/ ABL1( $(\Delta 674-695)$ mice $1-6)$. Between days 75 and 89 post BMT, seven of the remaining mutant-transplanted mice were killed and necropsies were performed. Five of these mice showed no obvious signs of disease, having normal WBC counts and spleen weights, and no observable lymphadenopathy (Figure 6b, Table 2, p210 BCR/ABL1( $(674-695)$ mice 8-10, 12 and 13$)$.
$\mathrm{GFP}^{+}$cells comprised less than $2 \%$ of the bone marrow, spleen and peripheral blood, which is equivalent to what we observed for vector-transplanted mice (Table 2). Although two of the killed mice showed evidence of disease progression (mice 11 and 14), their phenotype was consistent with T-cell leukemia. These mice presented with significant ascites and one had a large abdominal tumor (mouse 14). Flow cytometry performed on the peripheral blood, spleen, ascitic fluid and tumor of this mouse demonstrated an expansion of GFP ${ }^{+}$cells (Figure $6 \mathrm{c}$ ). Although all of these cells were negative for CD11b and B220 expression, a proportion did express the T-cell marker CD3. Two additional 
Table 1. Immunophenotyping of disease progression in a BMT assay for CML

\begin{tabular}{|c|c|c|c|c|c|}
\hline & $G F P^{+}$ & $\mathrm{GFP}^{+} / \mathrm{CD} 11 b^{+}$ & $\mathrm{GFP}^{+} / \mathrm{Gr} 1^{+}$ & $\mathrm{GFP}^{+} / \mathrm{CD}^{+}$ & $\mathrm{GFP}^{+} /{\mathrm{B} 220^{+}}^{+}$ \\
\hline Vector & $8.69 \pm 6.51$ & $4.78 \pm 1.44$ & $1.81 \pm 0.07$ & $0.046 \pm 0.04$ & $0.002 \pm 0.005$ \\
\hline$\Delta 674-695$ & $67.00 \pm 4.69$ & $57.50 \pm 5.97$ & $37.70 \pm 2.08^{* *}$ & $0.75 \pm 0.14$ & $4.38 \pm 1.01$ \\
\hline \multicolumn{6}{|l|}{ Bone marrow } \\
\hline Vector & $9.80 \pm 9.09$ & $7.41 \pm 3.97$ & $4.11 \pm 1.96$ & $0.64 \pm 0.30$ & $0.003 \pm 0.002$ \\
\hline \multicolumn{6}{|l|}{ Spleen } \\
\hline Vector & $5.67 \pm 3.74$ & $4.74 \pm 1.73$ & $2.37 \pm 0.88$ & $1.85 \pm 0.59$ & $0.005 \pm 0.003$ \\
\hline $\mathrm{BCR} / \mathrm{ABL}$ & $65.12 \pm 9.07$ & $39.97 \pm 17.11$ & $15.95 \pm 2.36$ & $2.94 \pm 1.44$ & $4.61 \pm 2.29$ \\
\hline$\Delta 674-695$ & $55.00 \pm 15.36$ & $47.05 \pm 14.56$ & $33.55 \pm 6.89^{*}$ & $1.08 \pm 0.52$ & $3.97 \pm 0.82$ \\
\hline
\end{tabular}
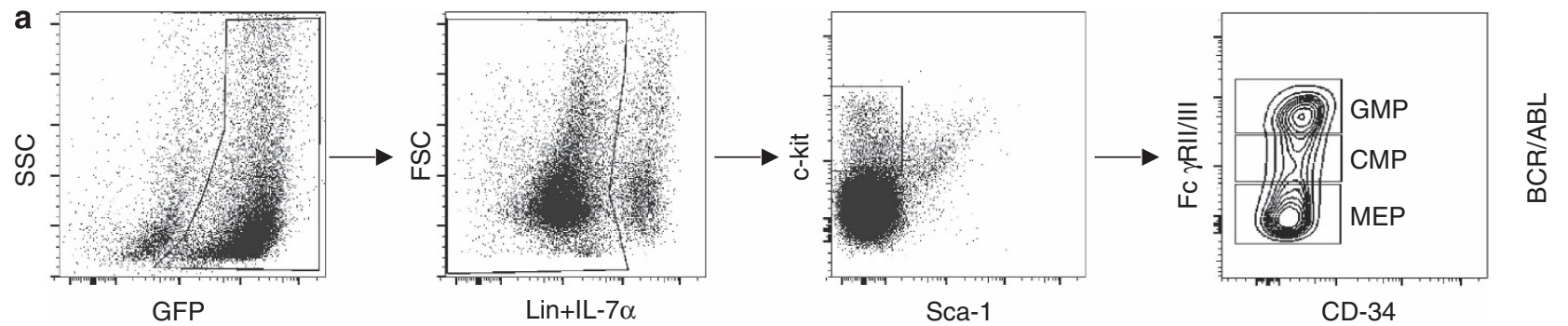

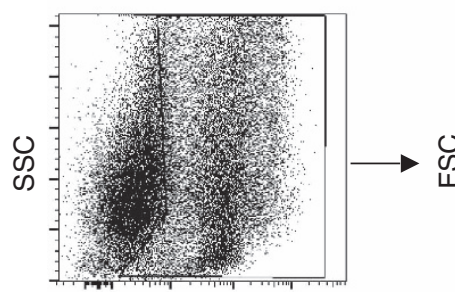

GFP

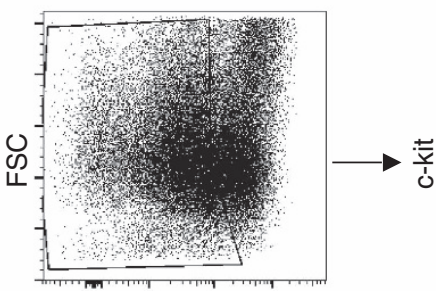

Lin+IL-7 $\alpha$

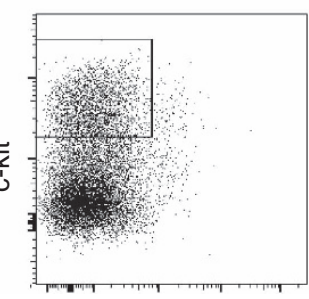

Sca-1
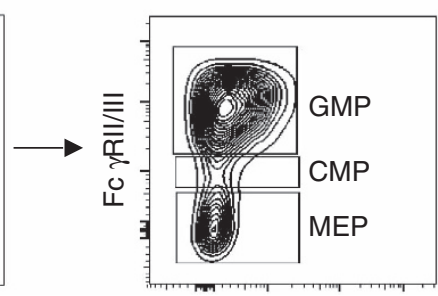

CD-34

b
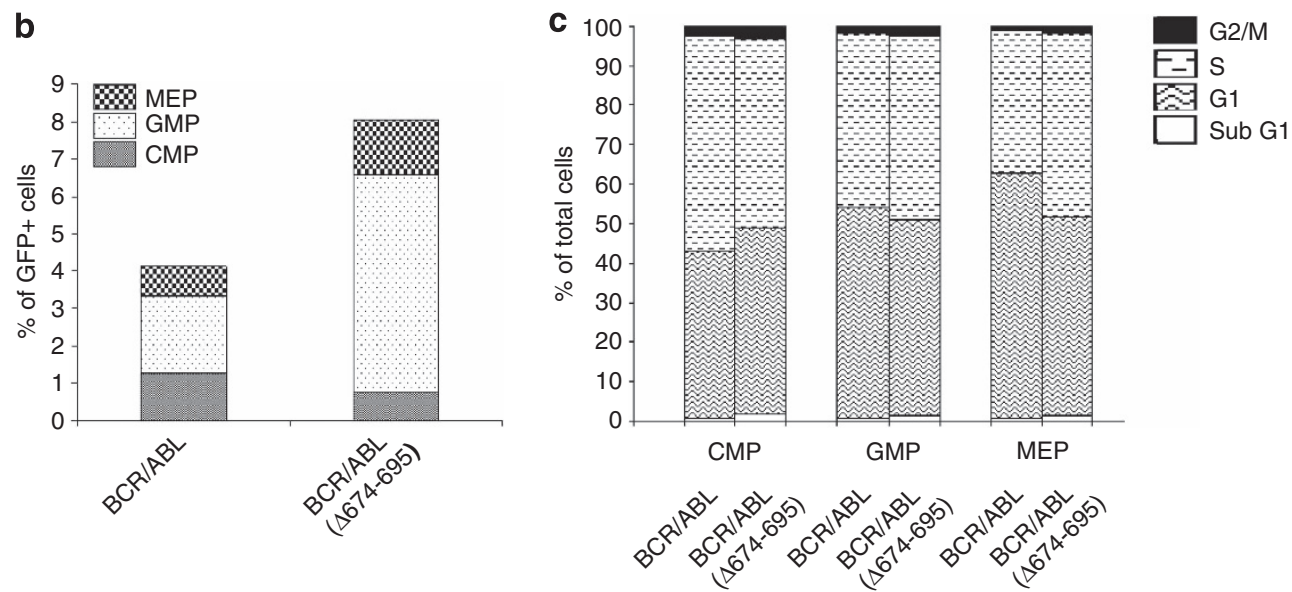

Figure 5. XPB binding limits the self-renewal of myeloid progenitors in p210 BCR/ABL1-transplanted mice. BMCs isolated from diseased mice at death were used for immunophenotypic and cell cycle analysis of progenitor populations. (a) Representative fluorescence-activated cell sorting staining profiles of progenitor populations. (b) Percentages of each progenitor populations (GMP, CMP and MEP) relative to total GFP ${ }^{+}$ cells. Values were derived from at least five mice per group and are represented as averages. Data show significant increase of GMP in BCR/ ABL1 $(\Delta 674-695)$ mice relative to BCR/ABL1 mice $(P<0.05))$. (c) Cell cycle analysis of CMPs, GMPs and MEPs in p210 BCR/ABL1 mice and p210 $\mathrm{BCR} / \mathrm{ABL} 1(\Delta 674-695)$ mice. Values were derived from at least five mice per group and are represented as averages. 
Table 2. Immunophenotyping of disease progression in a BMT model for ALL

\begin{tabular}{|c|c|c|c|c|}
\hline \multirow{2}{*}{$\begin{array}{l}\text { Mouse } \\
\text { (day at death or killing) }\end{array}$} & \multirow[t]{2}{*}{$\mathrm{GFP}^{+}$} & \multicolumn{3}{|c|}{ Peripheral blood (\% of total cells) } \\
\hline & & $\begin{array}{l}\mathrm{GFP}^{+} / \\
\mathrm{CD} 11 b^{+}\end{array}$ & $\begin{array}{l}\mathrm{GFP}^{+} / \\
{\mathrm{B} 22 \mathrm{O}^{+}}^{-}\end{array}$ & $\begin{array}{l}\mathrm{GFP}^{+} / \\
\mathrm{CD}^{+}\end{array}$ \\
\hline \multicolumn{5}{|l|}{ Vector } \\
\hline No. 1 (day 20) & 13 & 12 & 1 & 1 \\
\hline No. 2 (day 38) & 8 & 6 & 1 & 2 \\
\hline No. 3 (day 93) & 8 & 1 & 1 & 6 \\
\hline \multicolumn{5}{|l|}{ p210 BCR/ABL1 } \\
\hline No. 1(day 20) & 34 & 5 & 31 & $<1$ \\
\hline No. 2(day 20) & 21 & 15 & 15 & $<1$ \\
\hline No. 3(day 20) & 76 & 5 & 72 & 1 \\
\hline No. 4 (day 38) & 51 & 15 & 35 & 4 \\
\hline No. 5 (day 38) & 6 & 3 & 4 & 1 \\
\hline No. 6 (day 38) & 69 & 2 & 69 & 2 \\
\hline No. 7 (day 45$)^{a}$ & 15 & 4 & 13 & 1 \\
\hline No. $8{\text { (day } 47)^{a}}^{a}$ & 42 & 5 & 40 & 2 \\
\hline 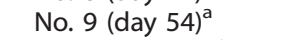 & 71 & 2 & 65 & $<\overline{1}$ \\
\hline 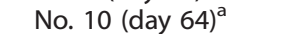 & 96 & 5 & 89 & 1 \\
\hline No. 11 (day 76) & 85 & $<1$ & 85 & $<1$ \\
\hline \multicolumn{5}{|l|}{ p210 BCR/ABL(4674-695) } \\
\hline No. 1(day 20) & 15 & 15 & 4 & 5 \\
\hline No. 2(day 20) & 6 & 6 & 1 & 1 \\
\hline No. 3(day 20) & 3 & 1 & 1 & 2 \\
\hline No. 4 (day 38) & 2 & 2 & 1 & 1 \\
\hline No. 5 (day 38) & $<1$ & $<1$ & $<1$ & $<1$ \\
\hline No. 6 (day 38) & $<1$ & $<1$ & $<1$ & 1 \\
\hline No. 7 (day 60) ${ }^{\mathrm{a}}$ & 2 & $<1$ & $<1$ & $<1$ \\
\hline No. 8 (day 76) & 1 & 1 & $<1$ & $<1$ \\
\hline No. 9 (day 77) & 1 & 1 & $<1$ & $<1$ \\
\hline No. 10 (day 77) & $<1$ & $<1$ & $<1$ & $<1$ \\
\hline No. 11 (day 80) & 33 & 3 & 4 & 23 \\
\hline No. 12 (day 80 ) & 2 & $<1$ & $<1$ & 1 \\
\hline No. 13 (day 89) & $<1$ & $<1$ & $<1$ & $<1$ \\
\hline No. 14 (day 89) & 11 & 2 & 1 & 3 \\
\hline No. 15 (day 106) & 3 & 2 & 1 & 1 \\
\hline No. 16 (day 106) & $<1$ & $<1$ & $<1$ & 1 \\
\hline
\end{tabular}

Abbreviations: ALL, acute lymphoblastic leukemia; BMT, bone marrow transplantation. Immunophenotyping was performed as described in Materials and Methods. ${ }^{a}$ Mice that succumbed due to disease. All other mice were electively killed.

mutant-transplanted mice were killed at day 106, and neither exhibited any signs of disease progression (Table 2, p210 BCR/ ABL1( $\Delta 674-695)$ mice 15 and 16$)$. To summarize, in all of the 16 mutant-transplanted mice that were killed and immunophenotyped, there was no evidence of B-cell proliferation in any organ that was examined.

Recipients receiving marrow infected with vector ( $n=20$ total) exhibited no sign of disease throughout the survival study (Table 2).

\section{DISCUSSION}

In the current study, we have demonstrated that disruption of the XPB interaction results in disease attenuation in BMT models of CML and B-ALL. In the model for CML, mice transplanted with the XPB-binding mutant exhibit increased survival. Myeloid expansion is primarily restricted to $\mathrm{Gr} 1^{+}$cells, which, in turn, is driving the disease phenotype. Although the number of GMPs at death in the mutant-transplanted mice is elevated, they show no increase in their proliferative potential.
This is consistent with the ex-vivo clonogenicity assays wherein the mutant is actually more limited in its ability to support the growth of GMP. As the disease phenotype appears to be restricted to a sub-lineage of GMPs, a larger number of GMPs may need to accumulate in order to achieve a tumor burden, resulting in morbidity. This would account for the substantially increased lifespan.

At day 16 post BMT, we observed an expansion of the $\mathrm{B} 220^{+}$ cells in the p210 BCR/ABL1-transplanted mice but not in the mutant. This expansion suggests that transformed lymphoid progenitors are engrafting earlier than myeloid progenitors and may be enjoying an early proliferative advantage. However, as the myeloid lineages expand, they may limit further expansion of the lymphoid progenitors. The failure of the mutant to drive lymphoproliferation was confirmed in a BMT model for B-ALL. Whereas the p210 BCR/ABL1-transplanted mice develop and succumb to a disease resembling human B-ALL, the mutanttransplanted mice either remained disease free or developed T-cell leukemias with long latencies. The ability of p210 BCR/ABL1 to drive T-cell leukemias has not been previously observed in the BMT model and suggests that it may be transforming a common lymphoid progenitor. Whereas the interaction with XPB in these cells supports lymphoid expansion, loss of the interaction may favor T-cell expansion.

As cells that express the XPB-binding mutant show lower levels of XPB phosphorylation on tyrosine, it is possible that p210 BCR/ $A B L 1$ transformation is influenced directly by XPB-associated activities, which may be altered by phosphorylation. It has been shown that tyrosine phosphorylation of XPB by p210 BCR/ABL1 reduces its ATPase and helicase activities in vitro, ${ }^{19}$ which is likely to result in both transcriptional and repair defects. Several studies indicate that the rate of NER is influenced by p210 BCR/ABL1, although opposing effects have been observed in lymphoid and myeloid cells. ${ }^{15,16}$ Although we observe similar effects of p210 $\mathrm{BCR} / \mathrm{ABL} 1$ on NER in Ba/F3 cells and primary murine myeloid cells, these effects do not appear to be dependent upon the interaction with XPB.

p210 BCR/ABL1 expression may also interfere with the transcriptional functions of TFIIH. A number of studies have documented altered transcription of specific target genes in response to p210 $\mathrm{BCR} / \mathrm{ABL} 1$ expression, including $\mathrm{C}-\mathrm{MYC}^{37}$, $\mathrm{BCl}-\mathrm{Xl}^{38}{ }^{38} \mathrm{PKC}^{39}$ and TRAIL. ${ }^{40}$ In addition, global changes in gene expression have been observed in 32Dcl3 myeloid cells that stably express p210 BCR/ABL1. ${ }^{41}$ Although some of these transcriptional changes can be attributed to alterations in STAT-regulated pathways, ${ }^{38}$ the interaction with XPB may represent a separate mechanism through which p210 BCR/ $\mathrm{ABL} 1$ can regulate transcriptional events. For example, recent studies suggest that expression of the c-myc gene, which is frequently upregulated in $\mathrm{CML}$, is controlled by a transcriptional complex that contains components of TFIIH, including XPB. ${ }^{32,33,42}$ We have previously shown that BCR is a nuclear protein that binds directly to c-MYC and inhibits its expression, thus suggesting that BCR may serve a regulatory function in this transcriptional complex. ${ }^{24}$ Our current observation that loss of XPB binding leads to reduced C-MYC expression suggests that p210 BCR/ABL1 may increase c-MYC expression by aberrantly regulating this complex. The reduction in c-MYC expression may also account for the reduced transforming activity of the mutant in both ex-vivo and in-vivo assays.

Collectively, our observations suggest that the interaction between XPB and p210 BCR/ABL1 supports disease progression in the murine model by influencing the differentiation potential of leukemic progenitors. The construction of a mutant that lacks the XPB-binding site may provide a unique opportunity to identify the factors present in these progenitors whose XPB-mediated expression supports leukemic expansion. This in turn may provide unique opportunities for therapeutic intervention. 

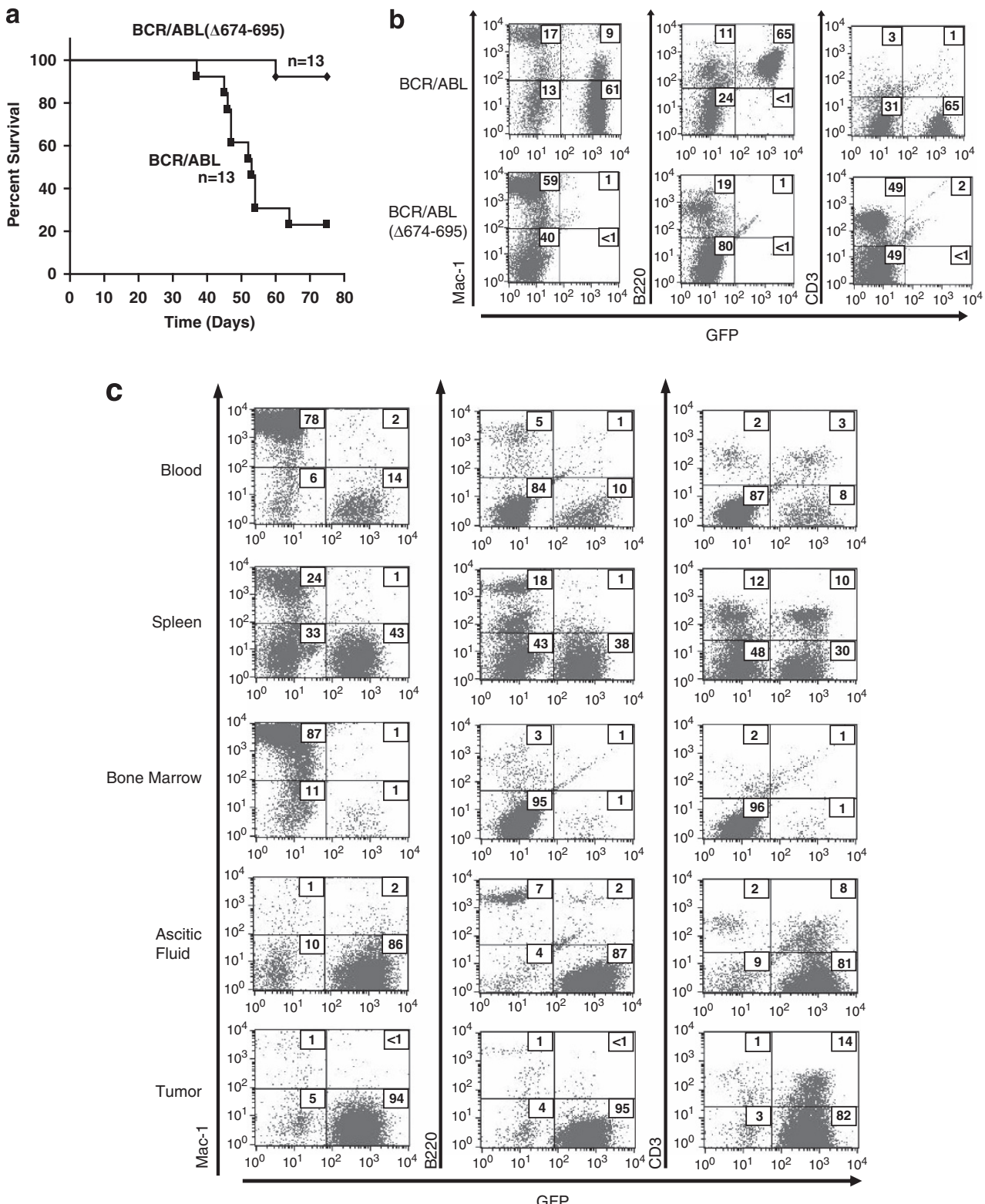

Figure 6. XPB binding supports lymphoproliferation in a murine model for B-ALL. (a) Survival of mice transplanted with p210 BCR/ABL1 or p210 BCR/ABL1( $\Delta 674-695)$. A Kaplan-Meier curve was generated for the first 75 days following BMT. A Mantel-Cox test yielded values of $P=0.0002$ and $\gamma^{2}$-test $=13.91$. (b and $\left.\mathbf{c}\right)$ Hematopoietic tissues were collected at the time of death and were examined by flow cytometry. Cells were stained for CD11b, B220 and CD3 as indicated. (b) Comparison of disease progression. On day 76, a p210 BCR/ABL1 (Table 2, p210

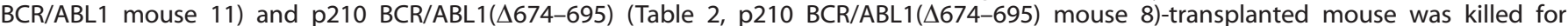
analysis. Results shown are from the bone marrow and are representative of both the blood and spleen. (c) A subset of the mutanttransplanted mice develop T-cell leukemias with long latency. On day 89, a p210 BCR/ABL1( $\Delta 674-695)$-transplanted mouse was killed for

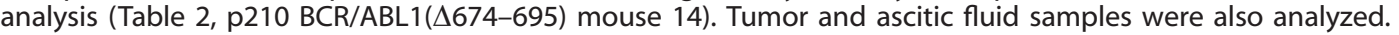

\section{CONFLICT OF INTEREST}

The authors declare no conflict of interest.

\section{ACKNOWLEDGEMENTS}

This work was supported by the Public Health Service grants CA097066 (IPW) and DK62757 (DAW). NLP, PLR and ERF is a recipient of a fellowship from the New Jersey Commission for Cancer Research. NLP are recipients of fellowships from NJCCR.

\section{REFERENCES}

1 Melo JV. The diversity of BCR-ABL fusion proteins and their relationship to leukemia phenotype. Blood 1996; 88: 2375-2384.
2 Muller AJ, Young JC, Pendergast AM, Pondel M, Landau NR, Littman DR et al. BCR first exon sequences specifically activate the $B C R / A B L$ tyrosine kinase oncogene of Philadelphia chromosome-positive human leukemias. Mol Cell Biol 1991; 11: 1785-1792.

3 McWhirter JR, Galasso DL, Wang JY. A coiled-coil oligomerization domain of Bcr is essential for the transforming function of Bcr-Abl oncoproteins. Mol Cell Biol 1993; 13: 7587-7595.

4 Maru Y, Afar DE, Witte ON, Shibuya M. The dimerization property of glutathione S-transferase partially reactivates Bcr-Abl lacking the oligomerization domain. J Biol Chem 1996; 271: 15353-15357.

5 Pendergast AM, Quilliam LA, Cripe LD, Bassing CH, Dai Z, Li N et al. BCR-ABLinduced oncogenesis is mediated by direct interaction with the $\mathrm{SH} 2$ domain of the GRB-2 adaptor protein. Cell 1993; 75: 175-185.

6 Calabretta B, Perrotti D. The biology of CML blast crisis. Blood 2004; 103: 4010-4022. 
7 Dierov J, Dierova R, Carroll M. BCR/ABL translocates to the nucleus and disrupts an ATR-dependent intra-S phase checkpoint. Cancer cell 2004; 5: 275-285.

8 Skorski T. BCR/ABL, DNA damage and DNA repair: implications for new treatment concepts. Leuk Lymphoma 2008; 49: 610-614.

9 Bedi A, Barber JP, Bedi GC, el-Deiry WS, Sidransky D, Vala MS et al. BCR-ABL-mediated inhibition of apoptosis with delay of G2/M transition after DNA damage: a mechanism of resistance to multiple anticancer agents. Blood 1995; 86: 1148-1158.

10 Fuchs EJ, Bedi A, Jones RJ, Hess AD. Cytotoxic T cells overcome BCR-ABL-mediated resistance to apoptosis. Cancer Res 1995; 55: 463-466.

11 Papazisis KT, Zambouli D, Kimoundri OT, Papadakis ES, Vala V, Geromichalos GD et al. Protein tyrosine kinase inhibitor, genistein, enhances apoptosis and cell cycle arrest in K562 cells treated with gamma-irradiation. Cancer Lett 2000; 160: 107-113.

12 Slupianek A, Schmutte C, Tombline G, Nieborowska-Skorska M, Hoser G, Nowicki $\mathrm{MO}$ et al. BCR/ABL regulates mammalian RecA homologs, resulting in drug resistance. $\mathrm{Mol}$ Cell 2001; 8: 795-806.

13 van der Kuip H, Goetz AW, Miething C, Duyster J, Aulitzky WE. Adhesion to fibronectin selectively protects Bcr-Abl + cells from DNA damage-induced apoptosis. Blood 2001; 98: 1532-1541.

14 Slupianek A, Hoser G, Majsterek I, Bronisz A, Malecki M, Blasiak J et al. Fusion tyrosine kinases induce drug resistance by stimulation of homology-dependent recombination repair, prolongation of $\mathrm{G}(2) / \mathrm{M}$ phase, and protection from apoptosis. Mol Cell Biol 2002; 22: 4189-4201.

15 Canitrot Y, Falinski R, Louat T, Laurent G, Cazaux C, Hoffmann JS et al. p210 BCR/ $A B L$ kinase regulates nucleotide excision repair (NER) and resistance to UV radiation. Blood 2003; 102: 2632-2637.

16 Laurent E, Mitchell DL, Estrov Z, Lowery M, Tucker SL, Talpaz M et al. Impact of p210(Bcr-Abl) on ultraviolet $C$ wavelength-induced DNA damage and repair Clin Cancer Res 2003; 9(10 Pt 1): 3722-3730.

17 Shuck SC, Short EA, Turchi JJ. Eukaryotic nucleotide excision repair: from understanding mechanisms to influencing biology. Cell Res 2008; 18: 64-72.

18 Maru Y, Kobayashi T, Tanaka K, Shibuya M. BCR binds to the xeroderma pigmentosum group B protein. Biochem Biophys Res Commun 1999; 260: 309-312.

19 Takeda N, Shibuya M, Maru Y. The BCR-ABL oncoprotein potentially interacts with the xeroderma pigmentosum group B protein. Proc Natl Acad Sci USA 1999; 96 203-207.

20 Roy R, Schaeffer L, Humbert S, Vermeulen W, Weeda G, Egly JM. The DNA-dependent ATPase activity associated with the class II basic transcription factor BTF2/TFIIH. J Biol Chem 1994; 269: 9826-9832.

21 Schaeffer L, Roy R, Humbert S, Moncollin V, Vermeulen W, Hoeijmakers JH et al. DNA repair helicase: a component of BTF2 (TFIIH) basic transcription factor. Science 1993; 260: 58-63.

22 van Vuuren AJ, Vermeulen W, Ma L, Weeda G, Appeldoorn E, Jaspers NG et al. Correction of xeroderma pigmentosum repair defect by basal transcription factor BTF2 (TFIIH). EMBO J 1994; 13: 1645-1653.

23 Sahay S, Pannucci NL, Mahon GM, Rodriguez PL, Megjugorac NJ, Kostenko EV et al. The RhoGEF domain of p210 Bcr-Abl activates RhoA and is required for transformation. Oncogene 2008; 27: 2064-2071.

24 Mahon GM, Wang $\mathrm{Y}$, Korus M, Kostenko E, Cheng L, Sun T et al. The c-Myc Oncoprotein Interacts with Bcr. Curr Biol 2003; 13: 437-441.

25 Van Parijs L, Refaeli Y, Lord JD, Nelson BH, Abbas AK, Baltimore D. Uncoupling IL-2 signals that regulate $T$ cell proliferation, survival, and Fas-mediated activation-induced cell death. Immunity 1999; 11: 281-288.
26 Naviaux RK, Costanzi $E_{\text {, Haas } M}$, Verma IM. The $\mathrm{pCL}$ vector system: rapid production of helper-free, high-titer, recombinant retroviruses. J Virol 1996; 70: 5701-5705.

27 Tala I, Chen R, Hu T, Fitzpatrick ER, Williams DA, Whitehead IP. Contributions of the RhoGEF activity of p210 BCR/ABL to disease progression. Leukemia 27: 1080-1089.

28 Olabisi OO, Mahon GM, Kostenko EV, Liu Z, Ozer HL, Whitehead IP. Bcr interacts with components of the endosomal sorting complex required for transport-I and is required for epidermal growth factor receptor turnover. Cancer Res 2006; 66: 6250-6257.

29 ten Hoeve J, Arlinghaus RB, Guo JQ, Heisterkamp N, Groffen J. Tyrosine phosphorylation of CRKL in Philadelphia + leukemia. Blood 1994; 84: 1731-1736.

30 Sawyers CL. The role of myc in transformation by BCR-ABL. Leuk Lymphoma 1993; 11(Suppl 1): 45-46.

31 Sawyers CL, Callahan W, Witte ON. Dominant negative MYC blocks transformation by ABL oncogenes. Cell 1992; 70: 901-910.

32 Liu J, Kouzine F, Nie Z, Chung HJ, Elisha-Feil Z, Weber A et al. The FUSE/FBP/FIR/ TFIIH system is a molecular machine programming a pulse of c-myc expression. EMBO J 2006; 25: 2119-2130.

33 Weber A, Liu J, Collins I, Levens D. TFIIH operates through an expanded proximal promoter to fine-tune c-myc expression. Mol Cell Biol 2005; 25: 147-161.

34 Li S, llaria Jr RL, Million RP, Daley GQ, Van Etten RA. The P190, P210, and P230 forms of the $B C R / A B L$ oncogene induce a similar chronic myeloid leukemia-like syndrome in mice but have different lymphoid leukemogenic activity. J Exp Med 1999; 189: 1399-1412.

35 Pear WS, Miller JP, Xu L, Pui JC, Soffer B, Quackenbush RC et al. Efficient and rapid induction of a chronic myelogenous leukemia-like myeloproliferative disease in mice receiving P210 bcr/abl-transduced bone marrow. Blood 1998; 92: 3780-3792.

36 Zhang $X$, Ren R. Bcr-Abl efficiently induces a myeloproliferative disease and production of excess interleukin-3 and granulocyte-macrophage colonystimulating factor in mice: a novel model for chronic myelogenous leukemia. Blood 1998; 92: 3829-3840.

37 Stewart MJ, Litz-Jackson S, Burgess GS, Williamson EA, Leibowitz DS, Boswell HS. Role for E2F1 in p210 BCR-ABL downstream regulation of c-myc transcription initiation. Studies in murine myeloid cells. Leukemia 1995; 9: 1499-1507.

38 Gesbert F, Griffin JD. Bcr/Abl activates transcription of the Bcl-X gene through STAT5. Blood 2000; 96: 2269-2276.

39 Gustafson WC, Ray S, Jamieson L, Thompson EA, Brasier AR, Fields AP. Bcr-Abl regulates protein kinase Ciota (PKCiota) transcription via an Elk1 site in the PKCiota promoter. J Biol Chem 2004; 279: 9400-9408.

40 Ghaffari S, Jagani Z, Kitidis C, Lodish HF, Khosravi-Far R. Cytokines and BCR-ABL mediate suppression of TRAIL-induced apoptosis through inhibition of forkhead FOXO3a transcription factor. Proc Natl Acad Sci USA 2003; 100: 6523-6528.

41 Hickey FB, Cotter TG. Identification of transcriptional targets associated with the expression of p210 Bcr-Abl. Eur J Haematol 2006; 76: 369-383.

42 Liu J, He L, Collins I, Ge H, Libutti D, Li J et al. The FBP interacting repressor targets TFIIH to inhibit activated transcription. Mol Cell 2000; 5: 331-341.

(i) $($ This work is licensed under a Creative Commons AttributionBY NC NonCommercial-NoDerivs 3.0 Unported License. To view a copy of this license, visit http://creativecommons.org/licenses/by-nc-nd/3.0/

Supplementary Information accompanies this paper on Blood Cancer Journal website (http://www.nature.com/bcj) 